\title{
Prostate Cancer Survivorship: Prevention and Treatment of the Adverse Effects of Androgen Deprivation Therapy
}

\author{
Philip J. Saylor, $M D^{7}$, Nancy L. Keating, MD, MPH', and Matthew R. Smith, MD, PhD ${ }^{7}$ \\ 'Division of Hematology-Oncology, Massachusetts General Hospital Cancer Center, Boston, MA, USA; ${ }^{2}$ Division of General Internal Medicine, \\ Brigham and Women's Hospital and Department of Health Care Policy, Harvard Medical School, Boston, MA, USA.
}

\begin{abstract}
BACKGROUND: More than one-third of the estimated 2 million prostate cancer survivors in the United States receive androgen deprivation therapy (ADT). This population of mostly older men is medically vulnerable to a variety of treatment-associated adverse effects.
\end{abstract}

MEASUREMENTS AND RESULTS: Androgen-deprivation therapy (ADT) causes loss of libido, vasomotor flushing, anemia, and fatigue. More recently, ADT has been shown to accelerate bone loss, increase fat mass, increase cholesterol and triglycerides, and decrease insulin sensitivity. Consistent with these adverse metabolic effects, ADT has also recently been associated with greater risks for fractures, diabetes and cardiovascular disease.

CONCLUSION: Primary care clinicians and patients should be aware of the potential benefits and harms of ADT. Screening and intervention to prevent treatmentrelated morbidity should be incorporated into the routine care of prostate cancer survivors. Evidence-based guidelines to prevent fractures, diabetes, and cardiovascular disease in prostate cancer survivors represent an important unmet need. We recommend the adapted use of established practice guidelines designed for the general population.

KEY WORDS: prostate cancer; survivorship; GnRH agonists; osteoporosis; bisphosphonates; diabetes; obesity; cardiovascular disease.

J Gen Intern Med 24(Suppl 2):389-94

DOI: $10.1007 /$ s11606-009-0968-y

(C) Society of General Internal Medicine 2009

\section{SCOPE OF THE PROBLEM}

Prostate cancer is the most common malignancy in men. The median age at diagnosis of prostate cancer is 68 years. ${ }^{1}$ Prostate cancer does not alter life expectancy for most of these men as the 5-year relative survival for all stages combined is $98.8 \%{ }^{1}$ Even those who present with metastatic disease have a median survival of approximately 30 months $^{2,3}$ and a 10-year survival approaching $10 \%{ }^{4}$ With improvements in cancer-specific survival, treatment-related morbidity has become more relevant to the long-term health of prostate cancer survivors.

Androgens can stimulate prostate cancer growth. Lowering androgen levels with androgen deprivation therapy (ADT) is the primary systemic treatment for prostate cancer. ADT is accomplished by either bilateral orchiectomies or medical castration with a gonadotropin-releasing hormone (GnRH) agonist. ADT achieves objective responses in over $80 \%$ of those treated. ${ }^{5,6}$ Most men are treated with a GnRH agonist rather than bilateral orchiectomies as GnRH agonists are easily administered, reversible, and more acceptable to patients. GnRH agonist use has risen markedly over the last 2 decades across all ages, disease stages and tumor grades. ${ }^{7,8}$ Currently, more than one-third of the estimated 2 million prostate cancer survivors in the United States are treated with GnRH agonists. ${ }^{9}$

$\mathrm{ADT}$ is the central treatment for metastatic prostate cancer as it improves bone pain, modestly prolongs overall survival and produces some 10-year survivors. ${ }^{10} \mathrm{GnRH}$ agonists have been shown to improve disease-free and overall survival in combination with radiation for locally advanced or high-risk nonmetastatic disease. ${ }^{11,12}$ Adjuvant therapy with a GnRH agonist also improves survival in men with node-positive disease after radical prostatectomy. ${ }^{13}$

ADT is also used for settings where evidence of benefit is less clear. PSA monitoring after primary therapy often detects recurrences long before symptoms or imaging would have revealed them. A rising PSA after primary surgery or radiation therapy commonly leads to long-term ADT, although the effects of early ADT for "PSA-only" recurrences on mortality have not been adequately characterized. ${ }^{14}$ Additionally, some men with localized disease opt for long-term ADT instead of radiation or surgery, a practice that has not been shown to improve survival relative to observation. ${ }^{15}$

The therapeutic effect of ADT is severe hypogonadism. GnRH agonists lead to a striking reduction in serum testosterone and a number of physiologic changes. Adverse changes in bone mineral density, body composition, lipid profile and insulin sensitivity are among the effects of GnRH agonist therapy. Men receiving GnRH agonists experience elevated risks for fracture, ${ }^{16}$ diabetes and cardiovascular disease, ${ }^{9}$ all of which cause substantial morbidity to elderly men at baseline.

With the introduction of PSA screening, fewer than 5\% of men have detectable metastases at presentation. ${ }^{17}$ Earlier diagnosis and more aggressive interventions have increased the burden of treatment for prostate cancer survivors.

Here we provide a focused review of the recently recognized complications of ADT: osteoporosis and fractures, obesity and sarcopenia, insulin resistance and diabetes, and cardiovascular disease. Readers are referred elsewhere for systematic reviews about these and other adverse effects of ADT. ${ }^{18,19}$ We also provide our recommendations for prevention and treatment of fractures, diabetes and cardiovascular disease in men treated with ADT. Our recommendations, detailed in Table 1, are adapted from broadly accepted practice guidelines from the National Osteoporosis Foundation (NOF), the American Diabetes Association (ADA), the 
Table 1. Recommendations for Men Receiving ADT for Prostate Cancer*

Osteoporosis

Screening: BMD testing for all men on ADT given the NOF recommendation for adults receiving a medicine associated with bone loss; test at baseline, repeat after 1 year of ADT, then repeat every 2 years or as clinically indicated

Treatment: Supplemental calcium $(\geq 1,200 \mathrm{mg}$ daily) and vitamin D (800-1,000 IU daily) for all and consideration of drug treatment if age $\geq 50$ and any of:

- Personal history of hip or vertebral fracture

- T-score $\leq-2.5$ at the femoral neck or spine (secondary causes evaluated)

- Low T-score at femoral neck or spine $(-1.0$ to -2.5$)$ and by US-adapted WHO algorithm:

- 10-year probability of a hip fracture $\geq 3 \%$ or

- 10-year probability of a major osteoporosis-related fracture $\geq 20 \%$

Diabetes and pre-diabetes

Screening:

- Consider testing in all men treated with ADT at baseline and yearly thereafter while receiving ADT

- Recommended test: fasting plasma glucose (FPG)

- Impaired Fasting Glucose (IFG) = FPG 100-125 mg/dl

- The use of hemoglobin AlC for the diagnosis of diabetes is not recommended

Treatment of pre-diabetes/IFG:

- For those identified with pre-diabetes, treat other CHD risk factors

- For those diagnosed with pre-diabetes, repeat testing at least yearly and counsel lifestyle interventions (with follow-up counseling):

- 5-10\% weight loss

- $\geq 150 \mathrm{~min} /$ week of moderate physical activity

Hyperlipidemia and CHD risk factors

Screening:

- Fasting lipoproteins at baseline, within 1 year of ADT initiation, then every 5 years or as clinically indicated

- Assign target LDL based on major CHD risk factors as outlined in NCEP ATP III

Treatment:

- Emphasis on primary prevention

- Tobacco cessation for all

- Treatment of hypertension per AHA guidelines

- Lifestyle interventions:

- Reduce intake of saturated fat and cholesterol

- Increase physical activity

- Weight control

- Low-dose aspirin in men with 10-year CHD risk $\geq 10 \%$

- Statins are first line for hyperlipidemia if lifestyle fails to meet target LDL

Key: $A D T$, androgen deprivation therapy; $B M D$, bone mineral density; LDL low density lipoprotein; CHD, coronary heart disease; FPG, fasting plasma glucose; IFG, impaired fasting glucose

* Our recommendations are adapted for the clinical situation from practice guidelines published by the National Osteoporosis Foundation (NOF), the American Diabetes Association (ADA), the National Cholesterol Education Program Adult Treatment Panel III (NCEPATP III) and the American Heart Association (AHA)

National Cholesterol Education Program Adult Treatment Panel III (NCEP ATP III) and the American Heart Association (AHA).

Evidence-based guidelines for men on ADT are lacking. This is due in part to the fact that these ADT-specific hazards were identified relatively recently and are still being fully defined. Moreover, few studies of various strategies to screen for and/or manage prostate cancer patients on ADT have been completed to date. Further clinical investigation is needed to better define the most effective strategies to promote health among prostate cancer survivors.

\section{OSTEOPOROSIS AND FRACTURES}

Fractures cause significant morbidity in men worldwide. ${ }^{20}$ One in three hip fractures occur in men. ${ }^{21}$ Hypogonadism, chronic glucocorticoid therapy and alcohol abuse are the most common causes of acquired osteoporosis in men. ${ }^{22}$

ADT accelerates bone turnover ${ }^{23,24}$, decreases bone mineral density ${ }^{23-28}$ and contributes to fracture risk. ${ }^{16,29,30}$ Analysis in the Surveillance, Epidemiology and End Results (SEER) Medicare database of over 50,000 older men with prostate cancer revealed that among those surviving 5 years beyond diagnosis, fracture rates were $19.4 \%$ in men who received ADT and $12.6 \%$ in men who did not. ${ }^{16} \mathrm{~A}$ second claims-based analysis in men with nonmetastatic prostate cancer similarly showed a significant association between GnRH agonist use and fractures (RR 1.21; P<0.001). ${ }^{29}$

Bisphosphonates including pamidronate, ${ }^{31,32}$ zoledronic acid $^{33,34}$ and alendronate ${ }^{35}$ have been shown to improve bone mineral density and decrease markers of bone metabolism in men on ADT. Notably, none of the completed studies was designed to prevent fracture.

Selective Estrogen Receptor Modulators (SERMs) have been tested for their effects on bone mineral density and markers of bone metabolism in men receiving ADT. Raloxifene ${ }^{36}$ and toremifene $^{37}$ are both SERMs that increase bone mineral density and decrease markers of bone metabolism in men treated with ADT. Recently, toremifene has been evaluated in a multicenter phase III study powered to demonstrate fracture prevention (see Table 2). The trial enrolled 1,389 men with low bone mineral density and/or age $\geq 70$ and randomized them to receive daily toremifene or placebo for 24 months. In a preliminary report, toremifene significantly decreased new vertebral fractures and increased bone mineral density at all measured skeletal sites. ${ }^{38}$

Receptor activator of nuclear factor-kappa-B ligand (RANKL) is a critical regulator of osteoclast differentiation, function and survival. ${ }^{39-43}$ Denosumab is a subcutaneously administered fully human monoclonal antibody against RANKL. It is in broad clinical development for postmenopausal osteoporosis, osteoporosis in cancer survivors and the prevention and treatment of bone metastases. Denosumab has been studied in a randomized, placebo-controlled fracture prevention trial that enrolled over 1,400 men at high risk for fracture due to ongoing ADT, older age and/or low bone mineral density (see Table 2). The study was completed in 2008; final results are pending.

Accurate assessment of fracture risk is necessary to identify which men are most likely to benefit from treatment. The World Health Organization/FRAX model improves fracture risk

Table 2. Completed Phase III Fracture Prevention Trials

\begin{tabular}{ccclc}
\hline \hline Study drug & $\mathbf{N}$ & Population & Arms & Endpoint(s) \\
\hline $\begin{array}{c}\text { Denosumab } \\
\text { (RANK-L } \\
\text { inhibitor) }\end{array}$ & $>1,400$ & $\begin{array}{c}\text { Current ADT, } \\
\text { high risk } \\
\text { due to old } \\
\text { age and/or } \\
\text { low BMD }\end{array}$ & $\begin{array}{c}\text { Denosumab } \\
\text { vs. placebo }\end{array}$ & $\begin{array}{c}\text { New vertebral } \\
\text { fractures, bone } \\
\text { mineral density }\end{array}$ \\
$\begin{array}{cccc}\text { Toremifene } \\
\text { (SERM) }\end{array}$ & 1,392 & $\begin{array}{c}\text { Current } \\
\text { ADT, } \geq 50\end{array}$ & Toremifene \\
& & vs. placebo & $\begin{array}{c}\text { Incident vertebral } \\
\text { fractures within }\end{array}$ \\
& & years old & & $\begin{array}{l}\text { 24 months, bone } \\
\text { mineral density, }\end{array}$ \\
& & & & lipid profile \\
\hline
\end{tabular}


assessment by incorporating a group of clinical risk factors in addition to femoral neck bone mineral density (http://www. shef.ac.uk/FRAX/index.htm). ${ }^{44-46}$ These clinical risk factors are based on large meta-analyses and include prior fragility fracture, family history of hip fracture, current tobacco smoking, chronic use of glucocorticoids, daily consumption of alcohol, rheumatoid arthritis and other conditions associated with secondary osteoporosis. ${ }^{41-54}$ Men receiving GnRH agonists are a high-risk population and should be screened for fracture risk with bone mineral density testing at baseline, after 1 year of ADT, then every 2 years or as clinically indicated (see Table 1).

The 2008 NOF guidelines recommend calcium $(\geq 1,200 \mathrm{mg}$ daily) and vitamin D (800-1,000 IU daily) supplementation for all men age 50 or over. The guidelines also recommend drug therapy for those who have low T-score $(-1.0$ to -2.5$)$ at the femoral neck or spine and 10-year risk of at least 3\% for hip fracture or at least $20 \%$ for any osteoporosis-related fracture according to the US-adapted FRAX model ${ }^{55}$ We believe that existing data clearly support considering ADT as a cause of secondary osteoporosis when using the FRAX tool. Although the ability of pharmacologic therapy to prevent fracture among men on ADT remains preliminary, the results of two phase III fracture prevention trials are anticipated soon.

\section{OBESITY AND SARCOPENIA}

Approximately one in three American men are obese [body mass index $\left.(\mathrm{BMI}) \geq 30.0 \mathrm{~kg} / \mathrm{m}^{2}\right] .{ }^{56}$ Androgens are important determinants of body composition as they promote lean body mass over fat mass. ${ }^{57}$ Conversely, ADT increases fat mass and decreases lean body mass. ${ }^{25,58}$

Prospective clinical trials have shown that 1 year of ADT causes approximately a $10 \%$ increase in fat body mass, a 3\% fall in lean body mass and $2 \%$ increase in overall weight. ${ }^{58-60}$ Cross-sectional imaging has revealed that abdominal girth increases during GnRH agonist therapy because of subcutaneous rather than intra-abdominal fat. ${ }^{58,61}$ Abdominal adiposity is a particular concern, as a very large prospective European cohort study found that waist circumference was strongly associated with risk of death even after adjustment for BMI. ${ }^{62}$ ADT-associated changes in body composition occur early in treatment, with significant rises in fat body mass ${ }^{63}$ as well as accompanying increases in plasma insulin ${ }^{63,64}$ occurring within 3 months of GnRH agonist therapy.

The optimal strategy to prevent or reverse these adverse changes in body composition during GnRH therapy is unknown. One study randomized 155 men to three-times-perweek resistance exercise or to a waiting list control group and found no difference in body composition between the groups at 3 months. ${ }^{65}$ Resistance training did provide some benefit in the form of less fatigue, higher quality of life and higher levels of muscular fitness. Further research on the treatment and prevention of ADT-associated changes in body composition is needed.

\section{LIPID ALTERATIONS}

GnRH agonists cause increases in total cholesterol (approximately 10\%), triglycerides (approximately 26\%) and high- density lipoprotein (HDL) (approximately 8-11\%), 58,66,67 and these changes have been observed after just 3 months of therapy. ${ }^{63,66}$ Clinician awareness of the potential for these changes can facilitate appropriate monitoring and management. We recommend fasting lipoproteins at baseline, within 1 year of ADT initiation and as clinically indicated thereafter.

Existing data strongly support a continuous, graded relationship between serum cholesterol and cardiovascular mortality. ${ }^{68,69}$ In the general population, the NCEP ATP-III guidelines define the standard-of-care ${ }^{70}$ Diet and lifestyle are first line interventions to achieve target low-density lipoprotein (LDL). When this is not successful, statins reduce all-cause mortality and are the first-line pharmacologic intervention. ${ }^{71}$

SERMs such as toremifene may benefit men with hyperlipidemia during ADT. A recently completed randomized placebocontrolled phase III trial was designed to primarily evaluate daily toremifene for fracture prevention in men receiving ADT. Planned interim analysis at 1 year demonstrated that toremifene decreases LDL cholesterol and triglycerides and increases HDL cholesterol compared to placebo. ${ }^{37}$ The effect of SERMs on cardiovascular outcomes is not yet known.

\section{INSULIN RESISTANCE}

Insulin resistance is associated with obesity and is an independent risk factor for diabetes and cardiovascular disease. Its prevalence in the general adult population is about $25 \% .^{72,73}$ Several small prospective studies have shown that GnRH agonists increase fasting insulin levels early in the course of GnRH agonist treatment. ${ }^{63,64,66}$ In a prospective study of nondiabetic men, ADT significantly decreased insulin sensitivity after 12 weeks. ${ }^{63}$ ADT did not significantly alter fasting plasma glucose levels, but did modestly increase glycated hemoglobin levels.

\section{DIABETES}

The incidence of diabetes has doubled in the last 30 years $^{74}$ and is projected to rise further. ${ }^{75}$ The National Health and Nutrition Examination Survey (NHANES) from 1999-2002 estimated the prevalence of diabetes in the population at $6.5 \%$, with another $2.8 \%$ undiagnosed. ${ }^{76}$ When these percentages are added to the $26.0 \%$ prevalence of impaired fasting glucose, more than a third of the US population either has diabetes or is at high risk for developing it.

Among 73,196 men in a SEER-Medicare database who were age 66 or older with locoregional prostate cancer, ${ }^{9} 36 \%$ were treated with a GnRH agonist and $7 \%$ underwent bilateral orchiectomy during follow-up (median of 4.55 years). The adjusted hazard ratio for incident diabetes was significantly higher among the men treated with GnRH agonists during follow-up (HR 1.44; $\mathrm{P}<0.001$ ). A preliminary report from a population-based study of Canadian men with prostate cancer confirmed the association between ADT and greater incidence of diabetes. ${ }^{77}$

Based on the prevalence of occult diabetes in older men and the observed association between ADT and greater incidence of diabetes, we recommend screening and intervention to reduce diabetes in line with guidelines from the ADA. ${ }^{78}$ Given the alterations in insulin sensitivity and the association of ADT 
with diabetes, we recommend testing of all men receiving longterm ADT at baseline and within 1 year of initiation (see Table 1). Fasting plasma glucose is the preferred diagnostic test and should be repeated yearly while on ADT. The use of AlC for the diagnosis of diabetes is not recommended. The ADA recommends counseling 5-10\% weight loss and at least $150 \mathrm{~min} /$ week of moderate physical activity to prevent or delay diabetes in those with impaired fasting glucose (fasting glucose $100-125 \mathrm{mg} / \mathrm{dl})$.

\section{CARDIOVASCULAR DISEASE}

Cardiovascular disease is the leading cause of death in the US and its prevalence rises with age. Obesity, insulin resistance and elevated triglycerides are all associated with ADT. Studies of ADT and cardiovascular disease are mixed. One analysis of the SEER-Medicare data demonstrated that men receiving GnRH agonists were more likely to develop incident coronary heart disease (HR 1.16; $\mathrm{P}<0.001$ ), myocardial infarction (HR 1.11; $\mathrm{P}=0.03$ ) and sudden cardiac death (HR 1.16, $\mathrm{P}=0.004){ }^{9}$ Another population-based study of 23,000 men with prostate cancer demonstrated a $20 \%$ rise in 1-year cardiovascular morbidity. ${ }^{79}$ A population-based observational study with relatively short follow-up (3.9 years) and few events (61) reported greater cardiovascular mortality in a subset of older men who underwent prostatectomy. ${ }^{80}$ Notably, this increase in cardiovascular morality was not apparent in the overall study population and traditional cardiovascular disease risk factors, including prevalent cardiovascular disease and diabetes, were not associated with cardiovascular mortality. A pooled analysis of three small randomized controlled trials of men with clinically localized prostate cancer suggested that 6 months of ADT led to earlier onset of fatal myocardial infarction in the subset of men at least 65 years old. ${ }^{81}$ This article's statistical methods have been criticized for the low number of observed events (16 in the control group and 18 in the ADT group). ${ }^{82}$

In contrast, a preliminary report from a population-based study of Canadian men with prostate cancer found no significant association between ADT and acute myocardial infarction. ${ }^{77}$ Secondary analyses of three large randomized controlled trials from the Radiation Therapy Oncology Group (RTOG) of men with locally advanced prostate cancer reported no association between neoadjuvant/adjuvant $\mathrm{ADT}$ and cardiovascular mortality. ${ }^{83-85}$ Similarly, secondary analyses of a randomized controlled trial from the European Organization for Research and Treatment of Cancer (EORTC) reported no association between ADT and cardiovascular mortality. Major strengths of the RTOG and EORTC studies include randomized study design, large sample size, long follow-up and a relatively large number of events.

Given the uncertain association between $\mathrm{ADT}$ and myocardial infarction, we recommend a standard emphasis on primary prevention as guided by NCEP ATP III and the American Heart Association (AHA) guidelines. Tobacco cessation and aggressive management of hypertension should be pursued for all. Low-dose aspirin is appropriate for men with at least 10\% 10-year risk of CHD. Lifestyle interventions should include weight control, regular physical activity, and reduced intake of saturated fat and cholesterol. Statins are first line for the treatment of hyperlipidemia if lifestyle interventions fail to bring LDL cholesterol to goal.

\section{CONCLUSIONS AND RECOMMENDATIONS}

For many men, prostate cancer is a chronic disease. As prostate cancer specific mortality has fallen to low levels, internists and oncologists commonly manage men with prostate cancer for years and sometimes for decades. ADT, the mainstay of treatment for recurrent and metastatic prostate cancer, has a variety of recently recognized adverse metabolic effects including osteoporosis, obesity, insulin resistance and lipid alterations. Recently, ADT has also been associated with greater risk for fractures, diabetes and cardiovascular disease. Recognition and prevention of these potential treatmentrelated harms are essential to promoting the health of prostate cancer survivors.

$\mathrm{ADT}$ increases the incidence of clinical fractures in prostate cancer survivors. All such men should be encouraged to take supplemental calcium $(\geq 1,200 \mathrm{mg}$ daily) and vitamin D (8001,000 IU daily). We advocate the use of the online WHO/FRAX fracture risk tool (http://www.shef.ac.uk/FRAX/index.htm) to estimate fracture risk in individual patients and identify candidates for pharmacologic intervention. The results of recently completed large phase III fracture prevention studies (see Table 2) will help establish evidence-based guidelines for fracture prevention for men receiving ADT.

Although insulin resistance and changes in body composition are both substantial burdens to men receiving ADT and associated with increased risk of diabetes, effective management strategies have not yet been established. In men and women at high risk for diabetes in the general population, the Diabetes Prevention Trial found that physical activity and weight loss reduced the incidence of diabetes by $58 \%$ compared with controls. This was almost twice the reduction achieved with metformin. ${ }^{86} \mathrm{~A}$ randomized trial of intensive lifestyle intervention in men treated with GnRH agonists is ongoing. This trial is designed to detect improvements in insulin sensitivity and markers of cardiovascular disease.

Cardiovascular disease and diabetes are two of the leading causes of non-cancer death among all patients with cancer ${ }^{87}$ and are particular concerns among men treated with GnRH agonists. We believe the best available management strategy is to employ broadly accepted practice guidelines for patients in the general population, including recommendations for management of hyperlipidemia, ${ }^{70}$ the detection and management of pre-diabetes and diabetes, ${ }^{78}$ and primary and secondary prevention of cardiovascular disease. ${ }^{88}$

Internists work with radiation oncologists, urologists and medical oncologists to promote the health of the growing population of medically vulnerable older men with prostate cancer. Survivorship research has defined many risks unique to this population. Awareness of the recently described adverse effects of GnRH agonists allows clinicians to educate, motivate and manage their patients to combat these changes. We anticipate that recently completed and ongoing trials will further guide our efforts to reduce treatment-related morbidity.

Acknowledgements: M.R. Smith is supported by an NIH K24 Midcareer Investigator Award (5K24CA121990-02) and grants from the Prostate Cancer Foundation and Lance Armstrong Foundation.

Conflict of Interest Statement: All three authors (Saylor, Keating and Smith) declare no conflict of interest related to the contents of this manuscript. 
Corresponding Author: Philip J. Saylor, MD; Division of Hematology-Oncology, Massachusetts General Hospital Cancer Center, Massachusetts General Hospital Lawrence House/POB: 2nd floor, 55 Fruit Street, Boston, MA 02114, USA (e-mail: psaylor@partners.org).

\section{REFERENCES}

1. Surveillance, Epidemiology and End Results (SEER): Stat Fact Sheets Prostate Cancer. 2008. (Accessed at http://seer.cancer.gov/statfacts/ $\mathrm{html} /$ prost.html).

2. Crawford ED, Eisenberger MA, McLeod DG, et al. A controlled trial of leuprolide with and without flutamide in prostatic carcinoma. $\mathrm{N}$ Engl $\mathrm{J}$ Med. 1989;321(7):419-24.

3. Eisenberger MA, Blumenstein BA, Crawford ED, et al. Bilateral orchiectomy with or without flutamide for metastatic prostate cancer. N Engl J Med. 1998;339(15): 1036-42.

4. Tangen CM, Faulkner JR, Crawford ED, et al. Ten-year survival in patients with metastatic prostate cancer. Clin Prostate Cancer. 2003;2 (1):41-5.

5. Leuprolide versus diethylstilbestrol for metastatic prostate cancer. The Leuprolide Study Group. N Engl J Med. 1984;311(20):1281-6.

6. Vogelzang NJ, Chodak GW, Soloway MS, et al. Goserelin versus orchiectomy in the treatment of advanced prostate cancer: final results of a randomized trial. Zoladex Prostate Study Group. Urology. 1995;46 (2):220-6.

7. Barry MJ, Delorenzo MA, Walker-Corkery ES, Lucas FL, Wennberg DC. The rising prevalence of androgen deprivation among older American men since the advent of prostate-specific antigen testing: a population-based cohort study. BJU Int. 2006:98(5):973-8.

8. Shahinian VB, Kuo YF, Freeman JL, Orihuela E, Goodwin JS. Increasing use of gonadotropin-releasing hormone agonists for the treatment of localized prostate carcinoma. Cancer. 2005;103(8):1615-24.

9. Keating NL, O'Malley AJ, Smith MR. Diabetes and cardiovascular disease during androgen deprivation therapy for prostate cancer. J Clin Oncol. 2006;24(27):4448-56

10. Walsh PC. Immediate versus deferred treatment for advanced prostatic cancer: initial results of the Medical Research Council trial. The Medical Research Council Prostate Cancer Working Party Investigators Group. J Urol. 1997;158(4): 1623-4.

11. Bolla M, Collette L, Blank $\mathbf{L}$, et al. Long-term results with immediate androgen suppression and external irradiation in patients with locally advanced prostate cancer (an EORTC study): a phase III randomised trial. Lancet. 2002;360(9327): 103-6.

12. D'Amico AV, Manola J, Loffredo M, Renshaw AA, DellaCroce A, Kantoff PW. 6-month androgen suppression plus radiation therapy vs radiation therapy alone for patients with clinically localized prostate cancer: a randomized controlled trial. Jama. 2004:292(7):821-7.

13. Messing EM, Manola $\mathbf{J}$, Yao J, et al. Immediate versus deferred androgen deprivation treatment in patients with node-positive prostate cancer after radical prostatectomy and pelvic lymphadenectomy. Lancet Oncol. 2006;7(6):472-9.

14. Loblaw DA, Virgo KS, Nam R, et al. Initial hormonal management of androgen-sensitive metastatic, recurrent, or progressive prostate cancer: 2006 update of an American Society of Clinical Oncology practice guideline. J Clin Oncol. 2007;25(12):1596-605.

15. Lu-Yao GL, Albertsen PC, Moore DF, et al. Survival following primary androgen deprivation therapy among men with localized prostate cancer. Jama. 2008;300(2):173-81.

16. Shahinian VB, Kuo YF, Freeman JL, Goodwin JS. Risk of fracture after androgen deprivation for prostate cancer. N Engl J Med. 2005;352 (2): 154-64

17. Ryan CJ, Elkin EP, Cowan J, Carroll PR. Initial treatment patterns and outcome of contemporary prostate cancer patients with bone metastases at initial presentation: data from CaPSURE. Cancer. 2007; 110(1):81-6.

18. Hakimian P, Blute M Jr., Kashanian J, Chan S, Silver D, Shabsigh R. Metabolic and cardiovascular effects of androgen deprivation therapy. BJU Int. 2008;102(11):1509-14.

19. Saad F, Adachi JD, Brown JP, et al. Cancer treatment-induced bone loss in breast and prostate cancer. J Clin Oncol. 2008;26(33):5465-76.

20. Ebeling PR. Clinical practice. Osteoporosis in men. N Engl J Med. 2008:358(14): 1474-82.

21. Seeman E. The structural basis of bone fragility in men. Bone. 1999;25 (1): 143-7.
22. Bilezikian JP. Osteoporosis in men. J Clin Endocrinol Metab. 1999;84 (10):3431-4.

23. Maillefert JF, Sibilia J, Michel F, Saussine C, Javier RM, Tavernier C. Bone mineral density in men treated with synthetic gonadotropinreleasing hormone agonists for prostatic carcinoma. J Urol. 1999;161 (4): 1219-22.

24. Smith MR, McGovern FJ, Zietman AL, et al. Pamidronate to prevent bone loss during androgen-deprivation therapy for prostate cancer. N Engl J Med. 2001;345(13):948-55.

25. Berruti A, Dogliotti L, Terrone $\mathbf{C}$, et al. Changes in bone mineral density, lean body mass and fat content as measured by dual energy $\mathrm{x}$ ray absorptiometry in patients with prostate cancer without apparent bone metastases given androgen deprivation therapy. J Urol. 2002;167 (6):2361-7. discussion 7

26. Daniell HW, Dunn SR, Ferguson DW, Lomas G, Niazi Z, Stratte PT. Progressive osteoporosis during androgen deprivation therapy for prostate cancer. J Urol. 2000;163(1):181-6.

27. Diamond T, Campbell J, Bryant C, Lynch w. The effect of combined androgen blockade on bone turnover and bone mineral densities in men treated for prostate carcinoma: longitudinal evaluation and response to intermittent cyclic etidronate therapy. Cancer. 1998;83(8):1561-6.

28. Smith MR, Eastham J, Gleason DM, Shasha D, Tchekmedyian S, Zinner N. Randomized controlled trial of zoledronic acid to prevent bone loss in men receiving androgen deprivation therapy for nonmetastatic prostate cancer. J Urol. 2003;169(6):2008-12.

29. Smith MR, Lee WC, Brandman J, Wang G, Botteman M, Pashos CL. Gonadotropin-releasing hormone agonists and fracture risk: a claimsbased cohort study of men with nonmetastatic prostate cancer. J Clin Oncol. 2005;23(31):7897-903.

30. Smith MR, Boyce SP, Moyneur E, Duh MS, Raut MK, Brandman J. Risk of clinical fractures after gonadotropin-releasing hormone agonist therapy for prostate cancer. J Urol. 2006;175(1):136-9. discussion 9.

31. Smith MR, McGovern FJ, Zietman AL, et al. Pamidronate to prevent bone loss in men receiving gonadotropin releasing hormone agonist therapy for prostate cancer. N Engl J Med. 2001;345(13):948-55.

32. Diamond TH, Winters J, Smith A, et al. The antiosteoporotic efficacy of intravenous pamidronate in men with prostate carcinoma receiving combined androgen blockade: a double blind, randomized, placebocontrolled crossover study. Cancer. 2001;92(6): 1444-50.

33. Smith MR, Eastham J, Gleason D, Shasha D, Tchekmedyian S, Zinner N. Randomized controlled trial of zoledronic acid to prevent bone loss in men undergoing androgen deprivation therapy for nonmetastatic prostate cancer. J Urol. 2003; 169(6):2008-12.

34. Michaelson MD, Kaufman DS, Lee $\mathbf{H}$, et al. Randomized controlled trial of annual zoledronic acid to prevent gonadotropin-releasing hormone agonist-induced bone loss in men with prostate cancer. J Clin Oncol. 2007:25(9): 1038-42.

35. Greenspan SL, Nelson JB, Trump DL, Resnick NM. Effect of onceweekly oral alendronate on bone loss in men receiving androgen deprivation therapy for prostate cancer: a randomized trial. Ann Intern Med. 2007; 146(6):416-24.

36. Smith MR, Fallon MA, Lee H, Finkelstein JS. Raloxifene to prevent gonadotropin-releasing hormone agonist-induced bone loss in men with prostate cancer: a randomized controlled trial. J Clin Endocrinol Metab. 2004;89(8):3841-6.

37. Smith MR, Malkowicz SB, Chu F, et al. Toremifene increases bone mineral density in men receiving androgen deprivation therapy for prostate cancer: interim analysis of a multicenter phase 3 clinical study. J Urol. 2008;179(1): 152-5.

38. Smith M, Morton R, Wallace $\mathbf{H}$, et al. A Phase III randomized controlled trial of toremifene to prevent fractures and other adverse effects of androgen therapy in men with prostate cancer. In: American Association for Cancer Research Annual Meeting 2008; 2008 April 12-16, 2008; San Diego, CA: AACR Meeting Abstracts Online; 2008.

39. Bekker PJ, Holloway DL, Rasmussen AS, et al. A single-dose placebocontrolled study of AMG 162, a fully human monoclonal antibody to RANKL, in postmenopausal women. J Bone Miner Res. 2004;19 (7): 1059-66.

40. Body JJ, Facon T, Coleman RE, et al. A study of the biological receptor activator of nuclear factor-kappaB ligand inhibitor, denosumab, in patients with multiple myeloma or bone metastases from breast cancer. Clin Cancer Res. 2006;12(4):122 1-8

41. Ellis GK, Bone HG, Chlebowski R, et al. Randomized trial of denosumab in patients receiving adjuvant aromatase inhibitors for nonmetastatic breast cancer. J Clin Oncol. 2008:26(30):4875-82. 
42. Lewiecki EM, Miller PD, McClung MR, et al. Two-year treatment with denosumab (AMG 162) in a randomized phase 2 study of postmenopausal women with low BMD. J Bone Miner Res. 2007;22(12):1832-41.

43. McClung MR, Lewiecki EM, Cohen SB, et al. Denosumab in postmen opausal women with low bone mineral density. N Engl J Med. 2006;354 (8):821-31.

44. De Laet C, Oden A, Johansson H, Johnell O, Jonsson B, Kanis JA. The impact of the use of multiple risk indicators for fracture on casefinding strategies: a mathematical approach. Osteoporos Int. 2005;16 (3):313-8.

45. Kanis JA, Johnell O, Oden A, De Laet C, Jonsson B, Dawson A. Tenyear risk of osteoporotic fracture and the effect of risk factors on screening strategies. Bone. 2002;30(1):251-8.

46. Kanis JA, Johnell O, Oden A, Johansson H, McCloskey E. FRAX and the assessment of fracture probability in men and women from the UK. Osteoporos Int. 2008; 19(4):385-97.

47. De Laet C, Kanis JA, Oden A, et al. Body mass index as a predictor of fracture risk: a meta-analysis. Osteoporos Int. 2005;16(11):1330-8.

48. Johnell O, Kanis JA, Oden A, et al. Predictive value of BMD for hip and other fractures. J Bone Miner Res. 2005;20(7):1185-94.

49. Kanis JA, Johansson H, Johnell O, et al. Alcohol intake as a risk factor for fracture. Osteoporos Int. 2005;16(7):737-42.

50. Kanis JA, Johansson H, Oden A, et al. A meta-analysis of milk intake and fracture risk: low utility for case finding. Osteoporos Int. 2005;16 (7):799-804.

51. Kanis JA, Johansson H, Oden A, et al. A family history of fracture and fracture risk: a meta-analysis. Bone. 2004;35(5):1029-37.

52. Kanis JA, Johansson H, Oden A, et al. A meta-analysis of prior corticosteroid use and fracture risk. J Bone Miner Res. 2004;19 (6):893-9.

53. Kanis JA, Johnell O, De Laet C, et al. A meta-analysis of previous fracture and subsequent fracture risk. Bone. 2004;35(2):375-82

54. Kanis JA, Johnell O, Oden A, et al. Smoking and fracture risk: a metaanalysis. Osteoporos Int. 2005;16(2):155-62

55. Watts NB, Lewiecki EM, Miller PD, Baim S. National Osteoporosis Foundation 2008 Clinician's Guide to Prevention and Treatment of Osteoporosis and the World Health Organization Fracture Risk Assessment Tool (FRAX): What They Mean to the Bone Densitometrist and Bone Technologist. J Clin Densitom 2008.

56. Bessesen DH. Update on obesity. J Clin Endocrinol Metab. 2008;93 (6):2027-34.

57. Vermeulen A, Goemaere S, Kaufman JM. Testosterone, body composition and aging. J Endocrinol Invest. 1999;22(5 Suppl):110-6.

58. Smith MR, Finkelstein JS, McGovern FJ, et al. Changes in body composition during androgen deprivation therapy for prostate cancer. $J$ Clin Endocrinol Metab. 2002;87(2):599-603.

59. Smith MR. Changes in fat and lean body mass during androgendeprivation therapy for prostate cancer. Urology. 2004;63(4):742-5.

60. Smith MR, Lee H, McGovern F, et al. Metabolic changes during gonadotropin-releasing hormone agonist therapy for prostate cancer: differences from the classic metabolic syndrome. Cancer. 2008;112 (10):2188-94

61. Smith MR, Lee H, Fallon MA, Nathan DM. Adipocytokines, obesity, and insulin resistance during combined androgen blockade for prostate cancer. Urology. 2008;71(2):318-22.

62. Pischon T, Boeing $\mathbf{H}$, Hoffmann $\mathbf{K}$, et al. General and abdominal adiposity and risk of death in Europe. N Engl J Med. 2008;359 (20):2105-20

63. Smith MR, Lee H, Nathan DM. Insulin sensitivity during combined androgen blockade for prostate cancer. J Clin Endocrinol Metab. 2006;91(4):1305-8.

64. Smith JC, Bennett S, Evans LM, et al. The effects of induced hypogonadism on arterial stiffness, body composition, and metabolic parameters in males with prostate cancer. J Clin Endocrinol Metab. 2001;86(9):4261-7.

65. Segal RJ, Reid RD, Courneya KS, et al. Resistance exercise in men receiving androgen deprivation therapy for prostate cancer. J Clin Oncol. 2003;21(9): 1653-9.

66. Dockery F, Bulpitt CJ, Agarwal S, Donaldson M, Rajkumar C. Testosterone suppression in men with prostate cancer leads to an increase in arterial stiffness and hyperinsulinaemia. Clin Sci (Lond) 2003;104(2): 195-201.

67. Eri LM, Urdal P, Bechensteen AG. Effects of the luteinizing hormonereleasing hormone agonist leuprolide on lipoproteins, fibrinogen and plasminogen activator inhibitor in patients with benign prostatic hyperplasia. J Urol. 1995; 154(1):100-4.

68. Lewington S, Whitlock G, Clarke R, et al. Blood cholesterol and vascular mortality by age, sex, and blood pressure: a meta-analysis of individual data from 61 prospective studies with 55,000 vascular deaths. Lancet. 2007;370(9602): 1829-39.

69. Stamler J, Wentworth D, Neaton JD. Is relationship between serum cholesterol and risk of premature death from coronary heart disease continuous and graded? Findings in 356,222 primary screenees of the Multiple Risk Factor Intervention Trial (MRFIT). Jama. 1986;256(20):2823-8

70. Third Report of the National Cholesterol Education Program (NCEP) Expert Panel on Detection, Evaluation, and Treatment of High Blood Cholesterol in Adults (Adult Treatment Panel III) final report. Circulation. 2002; 106(25):3143-421

71. Wilt TJ, Bloomfield HE, MacDonald R, et al. Effectiveness of statin therapy in adults with coronary heart disease. Arch Intern Med. 2004;164(13):1427-36.

72. Despres JP, Lamarche B, Mauriege P, et al. Hyperinsulinemia as an independent risk factor for ischemic heart disease. N Engl $\mathrm{J}$ Med. 1996;334(15):952-7.

73. Pyorala M, Miettinen H, Laakso M, Pyorala K. Hyperinsulinemia predicts coronary heart disease risk in healthy middle-aged men: the 22-year follow-up results of the Helsinki Policemen Study. Circulation. 1998;98(5):398-404

74. Fox CS, Pencina MJ, Meigs JB, Vasan RS, Levitzky YS, D'Agostino RB Sr Trends in the incidence of type 2 diabetes mellitus from the 1970s to the 1990s: the Framingham Heart Study. Circulation. 2006;113(25):2914-8.

75. Wild S, Roglic G, Green A, Sicree R, King H. Global prevalence of diabetes: estimates for the year 2000 and projections for 2030. Diabetes Care. 2004;27(5):1047-53.

76. Cowie CC, Rust KF, Byrd-Holt DD, et al. Prevalence of diabetes and impaired fasting glucose in adults in the U.S. population: National Health And Nutrition Examination Survey 1999-2002. Diabetes Care. 2006;29(6): 1263-8.

77. Allibhai SMD-H, M. Sutradar R., Fleshner N.E., Warde P., Cheung A M., Paszat, L. Impact of androgen deprivation therapy (ADT) on bone cardiovascular, and endocrine outcomes: A propensity-matched analysis of 20,000 patients. J Clin Oncol 2008 (May 20 suppl; abstr 5012).

78. Standards of medical care in diabetes-2008. Diabetes Care. 2008;31 (Suppl 1):S12-54.

79. Saigal CS, Gore JL, Krupski TL, Hanley J, Schonlau M, Litwin MS Androgen deprivation therapy increases cardiovascular morbidity in men with prostate cancer. Cancer. 2007;110(7):1493-500.

80. Tsai HK, D'Amico AV, Sadetsky N, Chen MH, Carroll PR. Androgen deprivation therapy for localized prostate cancer and the risk of cardiovascular mortality. J Natl Cancer Inst. 2007;99(20):1516-24.

81. D'Amico AV, Denham JW, Crook J, et al. Influence of androgen suppression therapy for prostate cancer on the frequency and timing of fatal myocardial infarctions. J Clin Oncol. 2007;25(17):2420-5.

82. Roach M 3rd. Regarding the influence of adjuvant suppression therapy for prostate cancer on the frequency and timing of fatal myocardial infarction: how real is the risk? J Clin Oncol. 2007;25(33):5325-6. author reply 6 .

83. Efstathiou JA, Bae K, Shipley WU, et al. Cardiovascular mortality and duration of androgen deprivation for locally advanced prostate cancer: Analysis of RTOG 92-02. Eur Urol. 2008

84. Roach M 3rd, Bae K, Speight J, et al. Short-term neoadjuvant androgen deprivation therapy and external-beam radiotherapy for locally advanced prostate cancer: long-term results of RTOG 8610. J Clin Oncol. 2008;26(4):585-91.

85. Efstathiou JA, Bae K, Shipley WU, et al. Cardiovascular mortality after androgen deprivation therapy for locally advanced prostate cancer: RTOG 85-31. J Clin Oncol. 2008.

86. Knowler WC, Barrett-Connor E, Fowler SE, et al. Reduction in the incidence of type 2 diabetes with lifestyle intervention or metformin. N Engl J Med. 2002;346(6):393-403.

87. Brown BW, Brauner C, Minnotte MC. Noncancer deaths in white adult cancer patients. J Natl Cancer Inst. 1993;85(12):979-87.

88. Pearson TA, Blair SN, Daniels SR, et al. AHA guidelines for primary prevention of cardiovascular disease and stroke: 2002 update: consensus panel guide to comprehensive risk reduction for adult patients without coronary or other atherosclerotic vascular diseases. American Heart Association Science Advisory and Coordinating Committee. Circulation. 2002;106(3):388-91. 